\title{
What Has Been Neglected in the Green Revolution? Developing Crop Poly-Genotype Varieties for Improving (Intra-Variety) Genetic Diversity in Agriculture
}

\author{
Xiaofang Li1,2, Huajun $\mathrm{Li}^{2}$, Qingyuan $\mathrm{Zou}^{3}$, Zhihao $\mathrm{Li}^{3}$, Mi Wang1, Chaofei $\mathrm{Xu}^{2 *}$ \\ ${ }^{1}$ Center of Crop Breeding Genetype Colony, Yangzte Universty, Jingzhou, China \\ ${ }^{2}$ Golden-Crown Agricultural LTD, Shenzhen, China \\ ${ }^{3}$ Guangzhou Nan-Guo Agricultural LTD, Guangzhou, China \\ Email: lixiaofang35@126.com,
}

Received 13 March 2014; revised 13 April 2014; accepted 18 April 2014

Copyright (C) 2014 by authors and Scientific Research Publishing Inc.

This work is licensed under the Creative Commons Attribution International License (CC BY). http://creativecommons.org/licenses/by/4.0/

c) (i) Open Access

\section{Abstract}

Modern agriculture, based on the improved single-genotype crop varieties and the intensive and monocultural managements, has contributed tremendously to the world's food supply. However, it is also challenged by stagnant yield growth, increasingly high input, mounting environmental pollution and pressing sustainability of development. In comparison, old agriculture of 100 years ago, based on the traditional multi-genotype landraces and low-input cultivation, prevailed thousands of years and still exists now in subsistence farming in marginal areas in spite of its low productivity. Crop multi-genotype breeding, which combines the advantages of both old and modern agriculture at the high level of productivity, will give us a promising strategy to break the predicament of modern agriculture. The concept, necessity, principle, technical tactics and characteristics of crop multi-genotype breeding are first elucidated in detail here. Two successful cases of application in rice and cotton are presented. Firstly, rice multi-genotype inbred varieties (colony variety) have commercialized using MAGIC lines. In cotton, a multi-genotype hybrid variety Jing-Mi 1 revealed superiority in seeded cotton and lint yields over the check variety in regional trial. Multigenotype variety could be maintained and recover the genetic diversity in production system. In their progenies of the MAGIC lines, most of them could be transmitted to the multi-genotype varieties, implying that the genetic diversity of agro-ecosystem could be effectively restored by crop multi-genotype varieties. We believe crop multi-genotype breeding will make a substantial contribution to restoring genetic diversity of agro-ecosystem, preventing the exacerbation of vulnerable environment and promoting the sustainable development of agriculture. We call for ever-in-

\footnotetext{
${ }^{*}$ Corresponding author.
}

How to cite this paper: Li, X.F., et al. (2014) What Has Been Neglected in the Green Revolution? Developing Crop Poly-Genotype Varieties for Improving (Intra-Variety) Genetic Diversity in Agriculture. Open Journal of Ecology, 4, $394-410$. http://dx.doi.org/10.4236/oje.2014.47035 
creasing efforts to develop and apply the crop multi-genotype breeding in agriculture.

Keywords

Biodiversity, Colony or Multi-Genotype Breeding, Crops

\section{Introduction}

Crop varieties are a major element and resource and the carrier of genetic diversity in agroecosystem. Modern agriculture, based on the improved single-genotype crop varieties and the intensive and monocultural managements, has contributed tremendously to the world's ever-increasing food supply. However, it is also challenged by stagnant yield growth, increasingly high input, mounting environmental pollution and pressing sustainability of development. Modern crop single-genotype breeding, which utilizes the principle of genetic segregation and recombination and has become overwhelmingly dominated up to now, attempts to create best super varieties through combining thousands of desired genes. This practice directly led to the decline of intra-variety genetic diversity and $75 \%$ of the genetic diversity was lost in the last century. As a matter of fact, no such super variety has been produced yet and the life span of current varieties has nevertheless been increasingly shortened. Furthermore, it is challenged by the sustainability of development. In comparison, old agriculture of 100 years ago, based on the traditional multi-genotype heterozygous landraces and low-input cultivation, prevailed thousands of years and still exists now in subsistence farming in marginal areas in spite of its low productivity. Crop polygenotype breeding, which combines the advantages of both old and modern agriculture at the high level of productivity, will give us a promising strategy to break the predicament of modern agriculture. We have explored and developed this new breeding technology in the past twenty years and now it is getting mature. The concept, necessity, principle, technical tactics and characteristics of crop multi-genotype breeding are first elucidated in detail here. Two successful cases of application in rice and cotton are presented. We believe this technology will make a substantial contribution to restoring genetic diversity of agroecosystem, preventing the exacerbation of vulnerable environment and promoting the sustainable development of agriculture. It will bring about a series of major transformation in agricultural production system and break the limitation of Green Revolution. It will add new values and elements beyond Green revolution. It will become a new engine for the next Green revolution and is thereby known to everybody globally.

Genetic diversity, together with biodiversity is currently one of hot topics including new energies and materials around the world. Up to now, major efforts have been made to save endangered species for conservation of species diversity in natural ecosystem, or have been concentrated on preserving diversified germplasm resources in crop plants or have been focused on revealing and characterizing the genetic diversity within those resources. Little work has been done about the species or genetic diversity in agroecosystems and genetic diversity within a specific variety has been nearly neglected. With the development of modern industrial civilization, it is getting more difficult to conserve the biodiversity and retain genetic diversity in natural ecological habitats. Are there any other approaches by which we can realize such a goal? As we known, agroecosystem takes up a major portion of global terrestrial areas. Thus it can be hopefully the largest carrier of genetic diversity for plants. If so, what changes have taken place in this agroecosystem during last century?

\subsection{Decline in Diversity of Cultivated Plant Species}

There are about 300,000 plant species which have been identified in the globe. Among them, around 3000 species were once cultivated and about 1200 were domesticated by human beings. However, only 150 species are adopted presently in the agricultural production, 29 plants of which contribute $90 \%$ of the consumed foods. Besides, major cereal crops comprise only 15 plant species [1].

\subsection{Drastic Reduction in the Number of Varieties for Cultivated Crop Plants}

The number of varieties in every crop plant has been reduced drastically in agriculture during the 20th century, leading to rapid decline in genetic diversity. In Greece, 95\% of the local wheat varieties were removed from 
1940s to 1980s. In South Africa, nearly all local sorghum varieties were replaced by imported varieties from US. Similar cases were reported for apple in France and muskmelon in Spain [2]. According to a report accredited by the Academy of Sciences of USA, the genetic diversity of agriculture has become increasingly fragile for most crop plants cultivated in the USA. Two varieties accounted for $40 \%$ of the planted area of winter wheat, only six soybean varieties were cultivated and nine peanut varieties accounted for $95 \%$ of the total yield [3]. China is the largest rice producing and consuming country in the world. It is also one of original places of rice diversity. In an incomplete statistic data, 46,000 rice varieties were cultivated in 1940s in China. In 1991, this figure slumped to about 1000 and 322 varieties were cultivated with annual planting acreages of more than 6667 hectares. According to a statistic report by the China Rice Data Centre, $90 \%$ of the approved Indica rice varieties were hybrid combinations from 2001 to 2008. Few conventional inbred varieties have been released and they had been extended for limited areas by seed companies due to economic drive. It has been estimated that hybrid combinations account for $90 \%$ of the planted area of Indica rice. The male-sterile genes of all those combinations are originated from less than 10 cytoplastic sources. Among them, combinations with sterile genes of wild-abortive type accounted for $90 \%$ of the planted areas and less than 200 sterile lines have been applied in large-scale seed production (http://www.ricedata.cn/variety/). For wheat, more than 13,000 varieties were planted in 1940s, over 1000 in 1970s in China. In 1990s, only 500 - 600 varieties were cultivated and 331 among them had large planted areas. For maize, there once existed more than 10,300 varieties in 1940s in China. By now, only 152 varieties have large planted areas and hybrid combinations accounted for $85 \%$ of the total planted areas. For seed rape, the number of varieties was reduced rapidly from 1600 in 1950s to less than 50 in 1990s and five varieties alone accounted for $90 \%$ of the planted areas [4]. Altogether, the world major crop plants have witnessed a rapid decrease in their variety numbers and this led to an amazing reduction of genetic diversity in agriculture.

\subsection{Manifestation of Reduced Genetic Diversity in Genic Alleles of Crop Varieties}

Using 36 microsatellite markers and 42 phenotypic traits, Yongwen Qi et al. analyzed genetic diversity of 453 rice varieties developed in China during a 50-year period from 1950 to 2000. It was shown that the number of alleles per studied locus was 9.10 on average in varieties bred in 1950s while this figure fell to 4.94 in those developed in 2000s, which is a $46 \%$ drop [5]. Similar results were also reported by Wei et al. in rice [6]. Through SSR analysis, Moon determined 294 alleles in 117 tobacco varieties developed from 1930s to 2000s and he found that only $48 \%$ of the original alleles, existing 70 years ago, were still kept in current varieties [7]. After analyzing 75 Canadian durum varieties, Yong-Bi Fu et al. confirmed that only 38\% of the original SSR markers were retained in 20 modern varieties [8]. Similar reports can be seen in other crop plants. It was estimated by FAO that about three-quarters of the genetic diversity of agricultural crops have been lost over the last century (http://www.fao.org/wfd/2004/).

\subsection{Unintentional Evolution in the Scope of Crop Variety Notion}

As the carriers of genetic diversity, crop varieties play a key role in agriculture. 100 years ago, crop variety was referred as a colony of plants within a species which were cultivated under natural production condition of agriculture to meet the requirements of ecodiversity. The English word "cultivar", a combination of cultivation and variety, highlights more on the practical function of such a colony. At that time, the modern genetics was not formed yet. The idea about genes and genotype were still ambiguous then. In fact, the crop plants were grown in natural populations with mixed and heterozygous forms. It was confirmed by Tu et al. that the previous landraces or farmer's varieties of rice were heterozygous mixtures in natural environments and wide genetic diversity were present in those landraces [9]. In 1953, the word of variety first appeared as a new term in taxonomy and it was adopted by the International Code for Nomenclature of Cultivated Plants (ICNCP). However, its exact definition was not made then. In 1975, James S. Pringle made such a definition about cultivar: a cultivated population of plants with distinct features to other populations within the same species, or a hybrid population within a species which combines various genetic traits for cultivation. It is developed through a single selection from an individual plant or a small and similar population. In reproduction, these individual plants maintain highly genetic consistency and are characterized with important horticultural or agronomical traits for their appearances and phenotypes [10]. In 1995, Brickell redefined it in ICNCP. He proposed that it is a taxonomical unit and it is selected due to one or many peculiar characters. It is featured with distinctiveness, conformity and stability and its characteristics can be maintained when multiplied properly. In modern agriculture, genetic homozygosity is high- 
lighted for a variety to achieve high consistency and controllability of seeds. As a matter of fact, it is unintentionally regarded as a highly homozygous, single-genotype and cloned population with a specific commercial objective. In English academic literature, the word of "variety" is more frequently used to highlight its status as a biological taxonomical unit and a specific form of genetic variation rather than its practical function in satisfying human beings and holding up genetic diversity [11]. Thus its concept is altered towards a more narrow scope. In US, EU, Japan, Australia, Russia, India and other countries, each has its own definition for crop varieties in their laws related to the protection of variety rights. Although both single and combined genotypes are mentioned in the definitions, little or no multi-genotype variety is involved in the application of IPR protection. Under most circumstances, only single-genotype varieties have been released and extended.

\subsection{Reformed Production Mode of Agriculture in Relation to Altered Notion of Crop Varieties}

At the beginning of last century, Mendel's law of inheritance was rediscovered and the science of genetics was founded at that time. Since then, artificial hybridizations were extensively conducted in various crop plants and their descendants were selected after segregation and recombination for elite single-genotype varieties. As a matter of fact, a modern variety is just a choice of optimal genotypes in a specific environment. A conventional inbred variety has a homozygous genotype while a hybrid combination owns a heterozygous one. These singlegenotype varieties have enhanced greatly the productivity of modern agriculture. For instance, G. S. Khush et al. from the International Rice Research Institute in Philippines developed a rice variety IR 8 in 1965 [12]. It was widely regarded as a heralding variety of rice in the Green revolution. It dramatically enhanced the grain yield of rice in South-East Asia and was called then miracle rice there. In the late 1950s, Yaoxiang Huang et al. from Guangdong Academy of Agricultural Science in China bred Guang-Chang-Ai, the world's first semi-dwarf variety of rice with sizable planting area [13]. The average yields of rice were thereby increased by $20 \%-30 \%$ in China [14]. Longping Yuan et al. invented the hybrid rice and it was the first successful heterosis utilization in self-pollinating crop plants [15]. With the rapid development in the technology of its hybrid seed production and realization of large-scale industrialization, hybrid rice has accounted for about $90 \%$ of planting areas of Indica rice by 2007 in China (www.cnrri.org/variety/shending/default.htm). Under the leadership of Norman E. Borlaug, a laureate of Nobel Peace Prize, wheat breeders in the International Maize and Wheat Improvement Center released the first semi-dwarf wheat varieties in Mexico and they were planted in around 35\% of the total area within three years. In 1966, the total wheat yield were enhanced five-fold compared with that of 1944 and Mexica became an exporting country in wheat [16]. India began to introduce wheat varieties from Mexico in 1966 and increased meanwhile its input in fertilizer, irrigation and farming mechanics. In 1980, the total yield was increased to 152,370,000 tons from the original 72,350,000 tons and India thus became an exporting partner from importing status in cereal trade. In the middle 20th century, the wide extension of maize hybrid combinations, developed from the T-type cytoplasm male sterile lines, dramatically enhanced the production of maize in US or even in the world-wide scope [3]. The above-mentioned events were some milestones in the Green Revolution. The major feature of those events lies in that the semi-dwarfication of crop plants was widely realized and singlegenotype varieties, instead of old landraces and natural populations, prevailed overwhelmingly in the production. With the enhanced yielding level, the input in water, fertilizers and pesticides were increased correspondingly as well. In the meantime, the number of crop varieties adopted in the production was increasingly diminished and the within-variety genetic diversities were nearly depleted.

\subsection{Adverse Consequence of Intensive Planting of Single-Genotype Crop Varieties in Agriculture}

The dominance of crop single-genotype varieties enhanced the productivity and changed the overall perspectives of agriculture in the last century. However, some seemingly adventitious incidents cast a shadow over its glory. In 1970, the outbreak of epidemic disease of Southern leaf blight (Bipolaris maydis) in maize brought about a 15\% loss to its total yield in US. This was mainly caused by the singularity of T-type cytoplasm in sterile lines, which were once admired fabulously [17]. In 1972, an abrupt fall of bitter cold led to a total harvest failure of winter wheat in 15 million hectares of lands in the former Soviet Union [2]. In an earlier year of 1846, occurrence of potato blight of singular imported varieties in Ireland caused 50 million persons to die with hungry and forced 200 million survivors to emigrate [1]. Crop epidemic diseases also took place frequently and repeatedly in China. 
In 1964, rust diseases of wheat prevailed in large areas where a variety Bi-Ma 1 was dominantly adopted in the production. It was discovered that the loss of resistance to new pathogen strain in this variety was attributed to a singular blood relationship. In a disease-serious year of 1993, an extraordinary disease of rice blast outbroke in 5.43 million hectares of inflicted areas and it resulted in a loss of one billion kilograms of grain. In the recent year of 2005, serious pests and diseases outbroke in major crop plants in extensive areas and brought about a tremendous loss in agriculture [18]. One of the underlying causes for all those events is the monoculture practice of single-genotype varieties bred with singular crop germplasms. The more this practice prevailed, the bigger would be the potential loss caused by the abrupt outbreak of pests and diseases.

\subsection{What Valuables Have Been Abandoned in the Green Revolution?}

In the long period of farming history before the twentieth century, the agricultural production of the world was mainly based on natural colonies of landraces or farmer's varieties with diversified genotypes, which are still used nowadays for some minor crop plants or planted for some major crop plants, such as rice, in marginal areas. After the Green Revolution, single-genotype varieties of crop plants including inbreeds and hybrids have been fully predominating in the entire agricultural production. The extensive adoption of these scientifically developed crop varieties that are high yielding and seemingly pest resistant, together with the intensive and monocultural managements of them, has contributed tremendously to the world's food production. Yet this practice has also led to serious "genetic erosion"- the loss of traditional varieties from agroecosystems and drastic cutback in the number of crop varieties. These were the two side-effect byproducts produced in this great Green Revolution. As shown above, reliance on a narrow spectrum of single-genotype varieties grown in monoculture has been linked to increased pest problems and vulnerable agroecosystems. Higher yields and greater food security have come at the expense of higher inputs of pesticides and fertilizers, which have brought along a long pollution chain from fields to dining tables. The sustainability of such a development model in agriculture has been questioned by a mounting number of agronomists [19] [20] and it is concerned by more and more populace.

Under such circumstance, increasing biological and genetic diversity has intrigued more and more scientists and agronomists worldwide. In particular, the decline of genetic diversity of crop plants in the production of agriculture has also been concerned or even highlighted in recent years, and some count measures, such as multiple lines, synthetic or mixed varieties and inter-cropping, were practiced in some places [21]-[26]. However, fundamental solutions to the problem are still missing by now and more practical strategies for new green revolution need to be further developed [19]. As a principal element of agriculture, crop varieties are the major application form of plants in agriculture and play a decisive role in modern agricultural production. If genetic diversity can be achieved within a variety, it will offer a thorough and fundamental approach to addressing the decline of genetic diversity in agroecosystems. Intra-variety genetic diversity can become a major form of application in exploiting genetic diversity in agriculture. In our opinion, modern improved varieties with high yield potential, if combined with the genetic diversity of traditional landraces, will contribute to (promote) the sustainable development of agriculture. Based on such considerations, we devised an innovative breeding strategy to fulfill intra-variety genetic diversity of crop plants in agriculture. Under this novel breeding strategy, stable multigenotype varieties will be bred and developed in crop plants, and the reproduction of their seeds will also be controlled accurately. The goal of our efforts is to restore the genetic diversity under the high-level productivity of modern agriculture. Consequently, it can be anticipated that the pests and diseases can be alleviated, the application of pesticides can be reduced, the safety of farm produce and food can be enhanced, the vulnerability of agroecosystems can be improved and the sustainable development of agriculture can be promoted. To fulfill this goal, we have in recent years attempted to develop multi-genotype varieties in some crop plants, such as rice and peanut (self-pollinating crop), maize (cross-pollinating crop) cotton (often cross-pollinating crop), sweet potato (asexually-cloned crop) and vegetable plants. Here we'll present some advances we've made in rice and cotton.

\section{Outlines of Crop Multi-Genotype Breeding}

\subsection{Definition}

Multi-genotype breeding is also known as genetic diversity breeding. In a Brief definition, it is a breeding strategy for creating and developing multi-genotype varieties artificially in crop plants. It comprises several concrete steps or processes as follows. Through multiple rounds of hybridizations, large quantities of stable and repro- 
ducible recombinants with various genotypes are created to form fundamental populations. By fully utilizing the effect of multiple mimic genes, multiple allelomorph and genotype complementation and through breaking ill or undesired linkages, stable individual plant lines in the fundamental population, which are different in genotypes but are consistent in phenotype and share specific characteristics in commodity attributes, will be selected and mixed in a specific ratio to form a multi-genotype variety. Their seeds will be multiplied exactly and then put into the production. The products finalized thereby are called multi-genotype, group or colony varieties for short.

\subsection{Overall Breeding Process}

According to the breeding targets, many appropriate male and female parents with excellent agronomical traits or some special characteristics will be chosen for hybridization. The number of parental lines also depends on the breeding objectives. Mutual complementation in many traits is unnecessary for a pair of male and female parents. However, adequate or full complementation in overall traits should be attained for all the parental lines and the balance in their traits should also be considered. Maximum number of recombinants should be created at the minimum cost of hybridization, such as convergent cross. After self-crossing for several generations, the progenies of hybrids will undergo genetic segregation and recombination until they become stable in both genotype and phenotype and finally form the fundamental population of multi-genotype breeding. During this course, selection will be performed and more individual plant lines should be retained as far as possible so that the maximum genetic diversity of them could be maintained. Subsequently, qualitative and quantitative characterizations in major agronomical traits will be conducted for all individual plant lines in the fundamental population. If necessary, the processes of selection and characterization can be done under different ecological conditions. All individual lines will be sorted on computer according to the collected data. Based on the computer assortment and breeder's judgments, those individual lines, which display consistent phenotype under different ecological conditions and conform to a same breeding objective, will be incorporated into a group to form a tentative multi-genotype variety. More than one or even dozens of tentative multi-genotype varieties can be developed from one fundamental population. A multi-genotype variety can made up of either inbred lines, hybrid lines, mixture of inbred and hybrid lines, or asexually-cloned lines. The original plant lines should be retained separately for the seed production of them. These tentative multi-genotype varieties will be further evaluated one or a couple of times for their comprehensive performance in the field. During this process, the component and proportion of a multi-genotype variety can be adjusted so that it can be perfected in yield, quality, resistance and other characters. After a multi-genotype variety is finalized, it will be put into regional trial, demonstration and extension.

In multi-genotype breeding of self-pollinating crops, large quantity of plant lines can be produced to form many multi-genotype varieties although it will take a longer time for the progenies of a convergent cross to become stabilized in comparison to the conventional breeding. In cross-pollinating crops which utilize heterosis, the F1 hybrids are the component lines of a multi-genotype variety [27]. In order to reduce the cost of pollen isolation in seed production, one single male line can be hybridized with multiple female lines and the proportion of each female line can be adjusted accordingly. In asexually-propagated crops, the clone lines are the component lines of multi-genotype varieties. As there is no sexual reproduction, the breeding duration can be shortened greatly. If a lot of existing intermediate breeding lines are available to breeders, they can be utilized directly to form multi-genotype varieties. Thus a flexible strategy should be adopted for different crops but the same aim to form a harmonious plant population should be followed [28]. In the below example of cotton, breeders just altered their breeding strategy and utilized existing lines at hand to develop directly multi-genotype hybrid varieties.

\subsection{Genetic Principles}

1) Widespread phenomenon of multi-genic effect or mimic genes: it has been proved in quantitative genetics that most agronomical traits of crop plants are quantitatively controlled by numerous small-effect genes. Recent molecular biological studies have identified the quantitative trait loci (QTLs) for many agronomical traits which are located in almost all chromosomes of the genome. A multi-gene-controlled trait may show numerous analogous phenotypes but it is essentially controlled by different genes. This phenomenon of multi-genic effect can often be observed in crop plants.

2) Widespread phenomenon of multiple allelomorphs: it has been demonstrated in molecular biology that 
crop plants widely display multiple allelomorph in a great many gene loci of agronomical traits. For example, rice has more than 37,000 - 40,000 gene loci [29] and most of the agronomical-related genes contain multiple alleles. A given permutation and combination of alleles at all 40,000 gene loci constitutes a specific genotype. Theoretically estimated, an infinite number of 240,000 genotypes can possibly be produced in rice through hybridization. As a matter of fact, only small portion of loci in the entire genome will display divergence between a pair of parental line. Even so, an astronomical number of genotypes can be still produced through a single cross between male and female lines which show only small difference for they contain at least thousands of locus differences. However, all genetic loci in one chromosome are combined together and only limited genetic recombinations can occur through homologous chromosome cross-over. So the number of genotypes produced in one cross will be relatively limited. As a whole, a large number of genotypes or varieties can be produced in rice through myriad crosses among various parental lines. In China, rice is the largest crop by variety counting and there are a total of around 6000 varieties which have once been used in the production. Through multi-genotype breeding, more alleles can be utilized effectively.

3) Widespread phenomenon of ill or undesired genetic linkage: It has been proved in genetics and breeding practices that ill or undesired genetic linkage is a widespread phenomenon in crop plants. For instance, blast-resistant lines of rice usually have low grain quality. Some ill linkages can be broken through genetic engineering. Due to complexity in permutations and combination of genes at thousands of loci, it is actually difficult to break those multiple ill-linkages in traditional breeding of single-genotype varieties. Usually, some desired traits are kept and others are lost. It will be easier to overcome the ill linkages through complementation among various genotypes and the probability of success will also be increased greatly. For example, some genotypes with strong disease resistance but ordinary grain quality can be complemented with other genotypes with ordinary resistance but high quality, and they can be combined to become a multi-genotype variety if they have equivalent yields. In general, more complementary benefits can be realized through multi-genotype breeding in crop plants. It was believed by McDonald [26] that the efforts to pyramid all desirable genes in one genotypte were unwise and this strategy was not sustainable. It would be easier for many resistance genes to be distributed over multiple lines than they are concentrated within a plant line.

4) Coarse Phenotypes versus exact genotypes: for the same phenotypes with no obvious difference, they actually comprise large numbers of different genotypes.

\subsection{Comparison with Existing Breeding Methods}

Firstly, the conventional single-genotype breeding is trying to select desired and superior individuals while the multi-genotype breeding is attempting to form an elite regiment of individuals by creating and combining a large number of new genotypes.

Secondly, multi-genotype varieties are different in breeding strategy with many existing alternative breeding approaches, such as multi-line variety, variety mixture, integrated variety and recurrent selection populations. Multi-genotype breeding also takes on some advantages over F1 hybrid breeding and transgenic breeding.

1) Multi-line varieties only utilize genetic diversity at one or a few gene loci while multi-genotype varieties make use of the genetic diversity at unlimited number of gene loci in the whole genome of a plant.

2) The integrated variety concept was first proposed and applied in the cross-pollinating plant maize [30]. In essence, integrated varieties are just mixtures of heterozygotes usually applied in broadening the genetic backgrounds of breeding lines. Their commodity products are usually not uniform and it is difficult to produce hybrid seeds exactly. In contrast, multi-genotype breeding can lead to homogeneous F1 hybrid seeds through controlling accurately the ratio of male and female plants. Their hybrid seeds can be stably produced for production. The dual advantages of heterosis and diversity can be also utilized in multi-genotype F1 hybrids.

3) Recurrent population selection is an effective route to accumulate elite genes in early breeding phases for population improvement. It was first utilized in maize and it was often applied in wheat by utilizing Tai-Gu genic male sterile lines. The recurrent selection populations were created by natural hybridization. However, its selection only focused on getting a single-genotype variety in traditional way [31]. In multi-genotype breeding, the recurrent selection populations could be used as a candidate of fundamental populations.

4) Cultivar Mixtures are just a mixture of pre-existing cultivars. Cultivar mixtures mentioned by Wolfe [21] and Mundt [23] for disease management are usually inconsistent in commodity attributes, being seldom applied 
in large scale production. Lammerts van Bueren [32] also supported developing multi-line varieties and cultivar mixtures to increase genetic diversity within a variety for organic agriculture. Mao et al. reported the control of rice blast through mixed planting of susceptible and resistant varieties [33]. McDonald et al. proposed that mixed or multi-line varieties be a sustainable strategy for coping with diseases [26]. In spite of their foreseeing contribution and efforts, breeders seldom turned these ideas to reality. Multi-genotype varieties are harmonious colony of newly-bred genotypes in order to create a new breeding system.

5) F1 hybrid breeding: As no sterile line is needed in multi-genotype breeding of self-pollinating plants, the risks of sterility can be thoroughly avoided. By controlling the stock seeds and protecting the seed formula (composition), market mechanism fit for hybrid seeds will also work for genetic diversity breeding. The costs of breeding will be lowered greatly and the costs for seed production are as low as that of conventional varieties.

6) Transgenic breeding: Although resistant varieties of transgenic plants can be developed by genetic engineering, the cost is very high. In addition, these transgenes with high intensity of resistance will put great specific selection pressure on targeted insects or microbes and usually lead to endogenous mutation of those target organisms. Consequently, either the plants will lose their resistance or strict refugee management strategies will have to be applied in agriculture or they will be infested by other new pests and diseases. For multi-genotype breeding, the plants can attain horizontal field resistance through their own genetic diversity and such resistance won't exert specific selection pressure on pest and disease organisms. The plants can display resistance to any possible pests and diseases and may prevent rampancy of a certain pest or disease. Therefore, their duration of resistance can be prolonged greatly in large areas. Transgenic breeding may be also adopted in multi-genotype varieties. However, different transgenes will be integrated strategically in the separate plant lines so that individual plant line will mutually provide "asylum" of each targeted organism to prevent rampancy of a certain pest or disease [34] [35]. In addition to these input traits, potential beneficial output traits such as nutritional quality parameters might be a target of inclusion of transgenic lines into multi-genotype varieties.

\section{Practice of Multi-Genotype Breeding in Rice}

\subsection{Parental Lines}

Adopting multiple and distant-related parental lines of hybridization is the prerequisite to achieve genetic diversity in multi-genotype breeding of rice. Multi-Parent Advanced Inter-Cross (MAGIC) of 12 parental plants used in diversity breeding program has released accuracy colony variety-Duo-Ji-Xin 3 [36] as commercialized.

Meantime after three rounds of hybridization, a total of more than 200 hybrids from MAGIC lines were produced and they were designated as A1, A2, ... A200. The MAGIC lines have abundant genetic diversity [37].

\subsection{Recombination and Stabilization through Selfing and Selection}

In the early segregation generations of above 200 hybrids, the descendant plants were multiplied through natural selfing, and twenty elite plants with diverse phenotypes were selected and retained for each plant line. The selfing courses proceeded for four or five generations until all plants in the entire population were stabilized in phenotype. In the end, 4000 plant lines, labeled as A1-1... A1-20..., A212-1...A200-20..., were finalized to become the fundamental population.

\subsection{Formation of Tentative Multi-Genotype Varieties}

392 elite plant lines originating from the initial 191 hybrids were selected from the fundamental population. According to their growth durations (days to heading/maturity) and plant heights at heading and maturity, plant lines were matched to form 20 tentative multi-genotype varieties, each of which were made up of 7 - 33 genotypes (plant lines) respectively.

\subsection{Trials of Rice Multi-Genotype Varieties}

The disease experiment was conducted in 2005 in Enshi, Hubei province of China, a most serious area of rice blast disease. Yue-Xiang-Zhan (YXZ) was the check variety. Seeds of 20 multi-genotype varieties and YXZ were sown in nursery beds. Seedlings at 5-leaf stage were transplanted in the field. 100 seedlings of each variety were planted in 4-row plots, 25 hills per row, 1 seedling per hill, spacing at $13.2 \mathrm{~cm} \times 20 \mathrm{~cm}$. One row of purple 
rice was planted between two plots. A total of 9 rows made up a sub-block, with a $50 \mathrm{~cm}$-wide aisle between two sub-blocks. Three rows of E-Zao 6, an elicitor variety of rice blast, were planted around the four sides of entire trial area. Leaf blast disease was investigated in the peak time of disease from the most active tillering stage to panicle initiation. The disease severities were scored in 9 grades according to the shape and size of disease speckles or spots, with 9 being the severest. Panicle blast diseases were investigated at the initial yellow ripe stage. 100 panicles were randomly selected and their diseases were scored by five grades: less than 5\% (Grade 1), 5\% - 20\% (Grade 2), 20\%-50\% (Grade 3), 50\% - 75\% (Grade 4) and 75\% - 100\% (Grade 5) loss of spikelets. The disease index was calculated below: ( $\Sigma$ scoring value $\mathrm{X}$ no. of samples falling in a grade)/(highest scoring value $X$ total no. of all samples). The yield and grain quality trial was conducted in the experimental farm of Yangtze University in Hubei province in 2005. The seedling raising was conducted in a same way of above disease trial. Each multi-genotype variety was planted in the plots with 50 plants (5 rows and 10 plants per row, spacing at $13.2 \mathrm{~cm} \times 20.0 \mathrm{~cm}$ ), with three replications and randomized complete block design. At maturity, 10 plants in the middle row of the plot were harvested for indoor examination of yield components, and their grain weights were converted to theoretical yield. The amylose content was determined and graded according to the state standard of China. Regular management of fertilizer, water and pests control was performed in the entire growth stages in both trials.

All multi-genotype lines and check variety fell in Grade 3 in leaf blast disease (Table 1), a slight-to-moderate severity, while those local varieties in adjacent fields showed more serious disease, higher than Grade 3 of leaf

Table 1. Blast disease resistance, grain quality and yield in 20 tentative multi-genotype varieties of rice.

\begin{tabular}{|c|c|c|c|c|c|c|}
\hline \multirow{2}{*}{ Code } & \multicolumn{2}{|c|}{ Blast Disease } & \multicolumn{2}{|c|}{ Amylose } & \multicolumn{2}{|l|}{ Grain Yield } \\
\hline & Panicle disease index (\%) & Leaf blast grade & Content (\%) & Grade & Theoretical yield $\left(\mathrm{Kg} / 667 \mathrm{~m}^{2}\right)$ & Standing \\
\hline JT1\# & 52.0 & 3 & 22.57 & 2 & 461.70 & 10 \\
\hline JT2\# & 33.6 & 3 & 23.00 & 2 & 653.40 & 1 \\
\hline JT3 & 38.0 & 3 & 23.84 & 3 & 589.05 & 3 \\
\hline JT4 & 76.8 & 3 & 25.27 & $>3$ & 215.06 & 19 \\
\hline JT5\# & 48.4 & 3 & 22.31 & 2 & 518.54 & 7 \\
\hline JT6 & 76.0 & 3 & 18.89 & 1 & 324.33 & 18 \\
\hline JT7 & 51.4 & 3 & 24.23 & $>3$ & 464.40 & 9 \\
\hline JT8\# & 47.2 & 3 & 20.53 & 1 & 508.73 & 5 \\
\hline JT9 & 73.0 & 3 & 19.87 & 1 & 372.64 & 16 \\
\hline JT10\# & 49.0 & 3 & 21.63 & 1 & 494.74 & 8 \\
\hline JT11 & 79.0 & 3 & 22.56 & 2 & 190.59 & 20 \\
\hline JT12 & 57.2 & 3 & 21.90 & 1 & 386.16 & 14 \\
\hline JT13\# & 45.2 & 3 & 22.26 & 2 & 535.56 & 4 \\
\hline JT14\# & 52.4 & 3 & 21.79 & 1 & 460.41 & 11 \\
\hline JT15 & 59.2 & 3 & 22.69 & 2 & 376.69 & 15 \\
\hline JT16 & 75.0 & 3 & 18.72 & 1 & 366.48 & 17 \\
\hline JT17\# & 53.2 & 3 & 19.08 & 1 & 457.28 & 12 \\
\hline JT18\# & 48.4 & 3 & 20.57 & 1 & 535.99 & 6 \\
\hline JT19 & 80.0 & 3 & 20.78 & 1 & 100.80 & 21 \\
\hline JT20\# & 37.2 & 3 & 20.37 & 1 & 639.19 & 2 \\
\hline CK & 53.6 & 3 & 24.57 & $>3$ & 451.34 & 13 \\
\hline
\end{tabular}


blast. The disease index of panicle neck blast lied between $33 \%$ and $60 \%$, being a moderate severity. The results indicate multi-genotype varieties could relieved both leaf and panicle blast, a most serious and widespread disease in rice. High amylose content is a major bottleneck in grain quality of Indica rice varieties. Multi-genotype varieties tended to display an intermediate level of amylose content, being closer to the state's standard of high grain quality of rice. Among the 20 tentative multi-genotype varieties, 11 ones arrived at grade 1 in amylose content $(17 \%-21 \%), 6$ ones were at grade $2(16 \%$ - 22\%) and one was at grade $3(15 \%-23 \%)$.This result far outpaces the performance of conventional breeding which usually produce $10 \%$ of lines overpassing Grade 3 . For grain yield, 12 multi-genotype varieties out yielded the check variety. Altogether, 10 multi-genotype varieties out-perform over check variety in yield, grain quality and resistance and they were symbolized with "\#” in the table. However, some multi-genotype varieties poorly performed in the trial, indicating that only proper matching among the component lines of a multi-genotype variety can achieve good and desirable performance.

Many successful cases has been documented about the application of multi-line varieties and mixed planting in controlling diseases, and they laid a theoretical foundation on multi-genotype breeding and offered alternative approaches in enhancing disease resistances.

\subsection{Summary of Multi-Genotype Breeding in Rice}

In the classical single-genotype breeding, thousands of descendants are produced from a single or a few crosses after segregation and recombination. Through repeated selection, only one or a couple of varieties are finalized while the other plant lines are eliminated.

In this study, 10 elite multi-genotype varieties were produced from a triple converging cross among 12 parental lines. Altogether, they comprised 191 genotypes and each of them contained on average 16 genotypes. As shown in Table 2, a multi-genotype variety composed of only 5 genotypes contains more than two alleles at loci

\section{Table 2. Range of growth duration and plant height in multi-genotype varieties.}

\begin{tabular}{|c|c|c|c|c|c|}
\hline Code & No. of genotypes & Days to heading & Plant height at heading (cm) & Days to maturity & Plant height at maturity $(\mathrm{cm})$ \\
\hline JT1 & 33 & $86-89$ & $63.5-67.5$ & $112-118$ & $89-93$ \\
\hline JT2 & 19 & $91-93$ & $66-68$ & $118-120$ & $107-109$ \\
\hline JT3 & 8 & $96-100$ & $70-72$ & $126-130$ & $116-118$ \\
\hline JT4 & 7 & $98-102$ & $69-71$ & $126-129$ & $117-119$ \\
\hline JT5 & 10 & $84-85$ & $58-68$ & $110-111$ & $101-103$ \\
\hline JT6 & 9 & $80-90$ & $53-67$ & $108-109$ & $92-102$ \\
\hline JT7 & 8 & $88-92$ & $63-65$ & $115-118$ & $80-87$ \\
\hline JT8 & 27 & $86-88$ & $64-66$ & $113-120$ & $104-106$ \\
\hline JT9 & 27 & $89-92$ & $64-66$ & $114-117$ & $104-106$ \\
\hline JT10 & 29 & $90-92$ & $64-66$ & $118-120$ & $104-106$ \\
\hline JT11 & 15 & $87-89$ & $70-71$ & $112-119$ & $110-112$ \\
\hline JT12 & 19 & $91-92$ & $70-72$ & $116-118$ & $110-112$ \\
\hline JT13 & 18 & 90 - 92 & $70-72$ & $119-120$ & $110-112$ \\
\hline JT14 & 12 & 89 - 92 & $66-68$ & $114-118$ & $113-114$ \\
\hline JT15 & 15 & $89-93$ & $69-70$ & $114-118$ & $113-114$ \\
\hline JT16 & 12 & $90-93$ & $66-69$ & $119-122$ & $113-114$ \\
\hline JT17 & 14 & 89 - 93 & $70-72$ & $119-122$ & $113-114$ \\
\hline JT18 & 16 & 90 - 97 & $66-68$ & $118-124$ & 115 \\
\hline JT19 & 10 & 95 - 97 & $69-72$ & $120-124$ & 115 \\
\hline JT20 & 12 & $91-93$ & $69-72$ & $118-123$ & 115 \\
\hline
\end{tabular}


conferring consistent phenotype. Thus it is foreseeable that multi-genotype varieties will greatly increase the genetic diversity of agroecosystem if they are extended in the production. We also found that the yield, resistance and grain quality of multi-genotype varieties would intend to be better with increased number of genotypes they contained. Rice is a lump-harvest crop. In order to control the consistency of multi-genotype varieties in commodity quality, growth duration, plant height and response to environment, the number of genotypes should be moderately reduced. Thus breeding procedures can be simplified and breeding efficiency can be enhanced.

We've studied the ecological responses of growth duration in the fundamental lines. We found that plant lines had higher ecological responses if they showed bigger difference in plant height between heading and maturity, or if their chlorophyll content of spade leaves decreased more rapidly during maturation [38] [39]. In order to increase the ecological adaptability of multi-genotype varieties, shuttle-breeding strategy should be adopted and their ecological responses should be determined through simple and quick methods. In addition, wide-adaptive and low-responsive lines should be incorporated in the multi-genotype varieties to enhance their consistency, adaptation and stability.

\section{Breeding of a Cotton Multi-Genotype Hybrid Variety Jing-Mi 1 and Its Performance}

As it has an indefinite inflorescence and its bolls are usually picked manually in the field, cotton won't have a high requirement for consistent growth duration. It has nevertheless a high requirement only for consistent cotton quality. As it is an often-self-pollinating crop, the multi-genotype varieties of cotton can be made up of either inbred lines or F1 hybrids. We developed a multi-genotype hybrid variety Jing-Mi 1 by utilizing existing elite breeding lines and evaluated its performance.

\subsection{Breeding Objectives and Selection}

Existing breeding lines with following characteristics were chosen as the male and female parental groups. Male parental group: relax and tower-shaped plant type, strong growth vigour, large, round and egg-shaped boll, growth duration of about 128 days, high tolerance to both Fusarium and Verticillium wilts and high pest resistance. Female parental group: relax and tower-shaped plant type, viridescent leaves, large and approximately round boll, high boll-setting rate, growth duration of about 123 days, high tolerance to both Fusarium and Verticillium wilts and high pest resistance.

Ten and eight lines were chosen respectively as the male and female parental groups for the above breeding objectives. Their pedigree origins and major agronomical characters were shown in Table 3.

\subsection{Hybrid Seed Production}

Seeds of the 10 and 8 lines in the male and female groups were mixed respectively in an equal proportion. The female and male groups were grown in an 8:2 row ratio in the fields. In blossom, the female parental plants in every 4 rows were pollinated with the male parental plants in one adjacent row.

\subsection{Regional Trial of Jing-Mi 1 in Hubei Province}

19 entries of newly developed inbred or hybrid varieties including Jing-Mi 1, plus the check variety E-Za-Mian 1 (EZM 1), were involved in the cotton regional trial of Hubei province in 2006. It was conducted simultaneously in five locations in Hubei province. Seeds were sown in the nourished pots in the early or mid-April. Pot-raised seedlings were transplanted in the fields. A randomized complete block design with three replications was adopted in all experimental spots. The fields were previously cropped in rotation with wheat or pea in two respective spots, or were fallowed in winter in the other three spots. The planting densities were $1480-2000$ plants per mu $\left(667 \mathrm{~m}^{2}\right)$. Pesticides were applied 8 - 10 times. 2 - 4 mid-cultivation weedings were conducted. Fertilizer levels of N, P, K per mu varied depending on the soil fertility, the highest or lowest level being 21.6 $\mathrm{Kg}, 9.1 \mathrm{Kg}, 32.1 \mathrm{Kg}$ and $9.79 \mathrm{Kg}, 4.5 \mathrm{Kg}, 4.5 \mathrm{Kg}$ respectively. The major agronomical traits, fiber quality and disease resistance were investigated.

The analysis of variance over all the 20 entries indicated that their seeded cotton and lint yields were significantly different. Jing-Mi 1 ranked at the 3rd and 4th place respectively in seeded cotton and lint yields among all 
Table 3. Pedigree origins of the male and female parental groups of Jing-Mi 1 and their major agronomical characters.

\begin{tabular}{|c|c|c|c|c|c|c|}
\hline $\begin{array}{l}\text { Parental } \\
\text { group }\end{array}$ & Code & Pedigree & $\begin{array}{c}\text { Growth } \\
\text { duration (d) }\end{array}$ & Bolls/Plant & $\begin{array}{l}\text { Weight/Boll } \\
\text { (g) }\end{array}$ & $\begin{array}{c}\text { Lint } \\
\text { percentage (\%) }\end{array}$ \\
\hline \multirow{10}{*}{$\begin{array}{l}\text { Male } \\
\text { group }\end{array}$} & D46 & D180-5 × San-Za-Mian 1-1 (line selection) & 131 & 46.7 & 5.4 & 40.6 \\
\hline & $\mathrm{D} 27$ & D180-1 & 129 & 43.4 & 5.4 & 41.6 \\
\hline & D29 & D180-6 × San-Za-Mian 1-2 (line selection) & 130 & 37.3 & 6.0 & 39.4 \\
\hline & D04 & D180-7 × TaiD5-1 ( line selection) & 128 & 46.8 & 5.8 & 41.3 \\
\hline & D48 & D180-8 × E-Za-Mian 4 (line selection) & 130 & 53.2 & 5.2 & 40.2 \\
\hline & D17 & D180-2 & 127 & 39.5 & 5.3 & 40.6 \\
\hline & D06 & D180-3 & 128 & 42.5 & 5.1 & 41.3 \\
\hline & D38 & D180-9 × Tai D5-2 ( line selection) & 126 & 46.1 & 4.8 & 40.7 \\
\hline & D20 & D180-10 × Tai D5-3 (backcross) & 129 & 37.4 & 5.9 & 41.6 \\
\hline & D22 & D180-4 & 127 & 46.2 & 4.3 & 40.9 \\
\hline \multirow{8}{*}{$\begin{array}{l}\text { Female } \\
\text { group }\end{array}$} & G17 & GK19-1 & 124 & 56.3 & 4.7 & 42.3 \\
\hline & G03 & GK19-5 × Jing-Feng A1-1 (line selection) & 128 & 64.3 & 4.6 & 41.5 \\
\hline & G01 & GK19-2 & 125 & 64.2 & 4.1 & 40.2 \\
\hline & G37 & GK19-6 × Jing-Feng A1-2 (line selection) & 127 & 59.2 & 4.3 & 41.7 \\
\hline & G27 & GK19-7 × HZ401 ( line selection) & 126 & 49.2 & 4.8 & 40.9 \\
\hline & G18 & GK19-8 × 98-7 (backcross) & 123 & 62.4 & 4.1 & 41.0 \\
\hline & G16 & GK19-3 & 124 & 58.3 & 4.7 & 40.1 \\
\hline & G11 & GK19-4 & 125 & 54.2 & 4.8 & 42.0 \\
\hline
\end{tabular}

the entries. T-test result showed that the average yields over the five locations of Jing-Mi 1 in both seeded cotton and lint were significantly higher than those of the check variety EZM 1.Its yield gains of seeded cotton and lint were $17.2 \%$ and $13.7 \%$ respectively over EZM 1 (Table 4). It was also found that the disease index of Verticillium wilt was 22.4 and 28.0 for Jing-Mi 1 and EZM 1 respectively. T-test showed that the former was significantly lower than the latter, indicating that Jing-Mi 1 was more resistant to this disease. The comprehensive evaluation for other characters of Jing-Mi 1 by the trial panel is as follows. "Medium plant height, compact and tower-shaped plant type, hair-thin stems, sub-medium leaf size, round and medium-size bolls. The growth vigor is quite strong at all stages. The boll-setting rate is high and the yield is good. The resistance to both Fusarium and Verticillium wilts is strong. The relative resistance index to Fusarium wilt is 16.4, and the relative resistance index to Verticillium wilt is 22.4.The growth duration is 125 days. The plant height is $123.8 \mathrm{~cm}$. The number of boll-bearing branches of individual plants is 17.5. The number of bolls of individual plants is 26.1. The weight of individual bolls is $5.8 \mathrm{~g}$. The 1000 -seed weight is $10.6 \mathrm{~g}$. The major and minor lint percentages are $40.6 \%$ and $42 \%$ respectively. The pre-frost lint rate is $95.1 \%$. The fiber quality is relatively low. The fiber length is 28.7 $\mathrm{mm}$, the fiber strength is $28.7 \mathrm{cN} / \mathrm{tex}$, the Micronaire (fiber fineness) is 5.0, and the fiber spinning uniformity index is 131.9. Major advantages: strong growth vigor, good boll-setting ability, fine yielding capacity. Major disadvantages: relatively low fiber quality." Overall, Jing-Mi 1 was superior in the performance of yield and disease resistance. However, Jing-Mi 1 displayed only an average level of fiber quality because it changed greatly among the individual plants. In the production, Jing-Mi 1 was highly welcomed and commended by farmers due to its superior yielding and disease resistance.

\section{Discussion and Prospects on Multi-Genotype Breeding in Crop Plants}

In the long farming history before the twentieth century, the agricultural production of the world was mainly based on natural colonies of landraces or farmer's varieties with diversified genotypes. During the last century, 
Table 4. Yielding performance of multi-genotype hybrid variety Jing-Mi 1 over multiple locations.

\begin{tabular}{ccccc}
\hline \multirow{2}{*}{ Location } & Variety & Seeded cotton yield $\left(\mathrm{Kg} / 667 \mathrm{~m}^{2}\right)$ & Lint yield $\left(\mathrm{Kg} / 667 \mathrm{~m}^{2}\right)$ & Bolls/Plant \\
\hline \multirow{2}{*}{ Wuhan } & Jing-Mi 1 & 251.7 & 135.1 & 20.6 \\
& EZM 1 & 184.6 & 79.8 & 20.2 \\
\multirow{2}{*}{ Jingchu } & Jing-Mi 1 & 250.4 & 105.4 & 31.5 \\
& EZM 1 & 227.0 & 91.9 & 28.2 \\
Longganhu & Jing-Mi 1 & 303.1 & 108.0 & 29.3 \\
& EZM 1 & 271.0 & 114.7 & 25.1 \\
Shayang & Jing-Mi 1 & 254.7 & 115.5 & 23.3 \\
& EZM 1 & 209.7 & 86.5 & 21.0 \\
Xiangfan & Jing-Mi 1 & 192.7 & 107.6 & 25.7 \\
& EZM 1 & 176.0 & 71.4 & 20.4 \\
Mean & Jing-Mi 1 & $250.5 \mathrm{a}$ & $101.1 \mathrm{a}$ & $26.1 \mathrm{a}$ \\
& EZM 1 (CK) & $213.7 \mathrm{~b}$ & $88.9 \mathrm{~b}$ & $23.0 \mathrm{~b}$ \\
\hline
\end{tabular}

improved single-genotype varieties of crop plants gradually replaced the former landraces and had finally dominated in the entire agricultural production. Meanwhile, a narrow spectrum of varieties has been grown in an intensive, monoculture manner. As a result of these two factors, modern agriculture has been experiencing an unprecedented decline in genetic diversity and it has also witnessed increased pest and disease problems, growing inputs of pesticides and fertilizers and vulnerable agroecosystems. Crop multi-genotype breeding, with a strategy to combine the advantages of both old landraces and modern improved varieties, will facilitate the restoration of genetic diversity of agroecosystem and it will bring us new thoughts, new forms of products and new producing systems in agriculture.

Perplexed by the decline of genetic diversity and challenged by the sustainable development of agriculture, many agronomists, breeders and plant scientists have once made painstaking efforts in the past. Zhu et al. [24] adopted inter-cropping of resistant and susceptible varieties to control rice blast disease. Mao et al. [33] also succeeded in controlling rice blast disease through mixed planting of resistant and susceptible varieties. Lammerts van Bueren [32] advocated utilizing multi-line varieties or variety mixtures to enhance genetic diversity in organic agriculture. Revill-Molina et al. (2009) reported mixed varieties could alleviate the lodging of rice [40]. Mundt ruled out the over-estimated difficulty of within-variety genetic diversity [23]. Ghaouti et al. developed synthetic cultivars of faba bean via breeding multi-lines to meet the requirements for low-input, stress-buffering and yield-stable varieties in organic agriculture [25]. He even proposed the adoption of landraces so that the features of stability and adaptability, which had been lost in the highly intensive single-genotype breeding, could be resumed. Marshall and Weir and Mundt also proposed the adoption of mixtures of varieties to control disease [22] [23]. All these reports point to the necessity of multi-genotype breeding in modern agricultural production, particularly in low-input organic agriculture, although their ahead-looking viewpoints were seldom concerned much by breeders and were never practiced as a breeding strategy. Here we report the multi-genotype breeding of self-pollinating inbred varieties of rice and often-self-pollinating hybrid varieties of cotton. As a primary breeding strategy, multi-genotype breeding can be transplanted in diverse crop plants and modifications should be made according to the characteristics of each crop.

\subsection{Classification of Multi-Genotype Breeding and Their Technical Features}

Crop multi-genotype varieties can be categorized according to their reproductive manner, harvest timing mode and genotypic homozygosity of component lines.

(1) Classification based on the reproductive characteristics

Self-pollinating crops: With minimum hybridization, maximum number of recombinants should be created. After repeated selfing and selection, large quantity of diverse and stable plant lines is formed in the fundamental 
population. After evaluation of their phenotypes, plant lines are matched to form multi-genotype varieties according to the breeding objectives. Considering the high costs of hybrids in both breeding and seed production and the potential risk of sterility, the inbred lines would be preferred candidates for developing multi-genotype varieties in self-pollinating crops. For rice, the grain quality of multi-genotype varieties will resemble the high quality of formulated/bagged rice in the stores.

Out-crossing crops: Scores of inbred lines with consistent commodity property are first selected. After evaluating the performance in hybrids of test crosses, one line with the best combining ability is selected as the male parent and other lines are used as female parents. The proportion of various female lines can be modified according to the breeding objectives and the performance of their hybrids. Hybrid seeds can be produced between this single male parental line and other female parental lines. In this way, both the multi-genotype and heterosis can be utilized and the cost of seed production can be lowered. As shown in this study of cotton, a male parental group, instead of just a single male line, can be alternatively crossed with female parental group to produce the hybrid seeds.

Asexually propagating crops: Given the sexual reproduction is possible, a multitude of new recombinant genotypes can be created through pyramiding or other ways of crosses. They can be asexually propagated and can directly become the fundamental population. After evaluation, selection and matching, new multi-genotype varieties can be formed from them.

Often-self-pollinating crops: If their self-pollinating property is utilized, a similar procedure adopted in selfpollinating crops should be followed: if their out-crossing property is utilized, a routine for out-crossing crops be followed. When they are multiplied, careful separation should be conducted to prevent the inadvertent out-cross and the resulting aberrant performance.

(2) Classification based on the harvest timing: lump-harvest and non-lump-harvest

For lump-harvest crops such as rice and wheat, the growth duration may become inconsistent due to the difference in temperature and photoperiod in different ecological regions where they are grown. For such a case, the multi-genotype varieties should be made up of genotypes with consistent growth duration. For those nonlump-harvest crops, such as cotton, melons and vegetables in particular which are mainly picked up manually or are sold dispersedly, the multi-genotype varieties should be made up of genotypes with different growth duration for an extended time of harvest and market supply.

(3) Classification based on genotypic homozygosity of component lines

The multi-genotype varieties can be made up of homozygotic inbred lines, heterozygotic hybrid lines or a mixture of inbred and hybrid lines.

Although each type of crops has its own characteristics in multi-genotype breeding, consistency in commodity property is the common objective of multi-genotype breeding in all crops. Considering the cost of breeding and seed production, it is not right to say that the maximal genetic diversity is the optimal choice. The most important thing is to maintain a feasible balance between the quantity of genotypes and the consistency in commodity property. Apart from rice and cotton, we've also conducted multi-genotype breeding in seed rape, peanut, sweet potato, cucumber and corn etc.

\subsection{Major Transitions Brought about by Crop Multi-Genotype Breeding in Agriculture}

(1) Ideological transition in selection: In single-genotype breeding, only one or a couple of elite individual plant lines are selected for a variety from thousands of descendants of a cross. In multi-genotype breeding, thousands of plant lines are retained as the fundamental population and a group of individual plants rather than a single plant are selected for a variety.

(2) Scope extension of crop variety notion: In conventional notion, crop varieties are featured with conformity, stability and distinctiveness. Although the requirements for stability and distinctiveness remain still unchanged in multi-genotype varieties, the criterion for conformity can be moderately relaxed and is mainly reflected in the phenotype rather than the genotype. For some characters, such as maturity in non-lump-harvest crops, even the criterion for phenotype conformity can be flexible as well.

(3) Restoration of genetic diversity in agroecosystem: Compared to single-genotype varieties, multi-genotype varieties will increase by at least one-fold the genetic diversity (alleles per locus) of agroecosystem when they are grown in a same area with equal number of varieties. The effect of enhancement will depend on the quantity of genotypes encompassed in a multi-genotype variety. With the extension of multi-genotype varieties, 
the agroecosystem will become less vulnerable to pests and diseases. Because of its effect in enhancing genetic diversity, multi-genotype breeding can be also called genetic diversity breeding.

\subsection{Marketing Perspectives-Acceptance and Drive of Multi-Genotype Varieties by Seed Companies}

For self-pollinating crops, seeds of conventional inbred varieties can be reserved by farmers for planting for many generations, and farmers have low incentive to purchase seeds in the market. Seeds of hybrid varieties can be used for only one generation and must be exclusively produced by seeds companies. In spite of the high cost and potential risks, hybrid varieties of crops were promoted actively by seed companies and breeders due to economical drives. As the proportion and multiplication coefficients are different among various genotypes in a given multi-genotype variety, its characteristics will change if its seeds were reserved for the next planting. So the seeds of multi-genotype varieties must also be produced exclusively by seed companies and the seeds supply will be controlled by them as well. Like conventional varieties, the simple procedure and low cost for seeds production of multi-genotype varieties is another attraction to seed companies. In no doubt, multi-genotype varieties can be definitely accepted by seed companies and will be promoted actively by them.

\subsection{New Theoretical and Practical Problems Encountered in Multi-Genotype Breeding}

As mentioned above, the scope of variety notion is widened in multi-genotype breeding. However, this new notion must be widely accepted by agronomists and farmers, and first of all by policy-makers of agriculture. Under this breeding system, many new theoretical and practical problems will come out. For instance, phenotype consistency will be of particular implication and importance in crop multi-genotype breeding. For lump-harvest crops, what's the allowed range of variation in maturity and plant height? How can we fast and simply determine the consistency? For non-lump-harvest crops, how can the discrepancy in maturity be utilized in the production? As multi-genotype varieties can display comparative superiority in yielding and disease resistance over their component lines, then are there any complementary or synergistic effects or any other underlying mechanisms? When they are extended in different regions, the ecological adaptability of multi-genotype varieties must be concerned and the long-term ecological impact they will have on the environment need also to be considered. Apart from these problems, many other special phenomena/issues will appear and need to be addressed in the future.

Multi-genotype varieties in crop, a fine combination of old landraces and modern improved variety will bring along a new generation of technology renovation and will produce a profound impact in the new era of agriculture [41]. We believe the value of crop multi-genotype breeding will be gradually appreciated by agronomists, seed companies and farmers and multi-genotype varieties will be finally accepted by them. We hope more efforts to be made to the perfection of this epoch-making technology in agriculture.

\section{Acknowledgements}

We are owing to Mr. Liu Yan-Zhuo for his aids in English revision.

\section{Funding}

This research was supported by Special Fund for Agro-Scientific Research in the Public Interest (\#201303008) and the National Science Foundation of China (\#31071482).

\section{References}

[1] Esquinas-Alcazar, J.T. (1987) Plant Genetic Resources: A Base for Food Security. CERES, Rome, 9-45.

[2] Plucknett, D.L., Smith, N.J.H., Williams, T. and Hetty, N.M. (1983) Crop Germplasm Conservation and Developing Countries. Science, 220, 163-169. http://dx.doi.org/10.1126/science.220.4593.163

[3] National Research Council (1972) Genetic Vulnerability of Major Crops. Academy of Science Press, Washington DC.

[4] Liu, J. and He, K. (1997) Agricultural Almanac of China. China Agricultural Press, Beijing, 490-492.

[5] Qi, Y.W., Zhang, D.L., Zhang, H.L., Wang, M.X., Sun, J.L., Liao, D.Q., et al. (2006) The Genetic Diversity and Changing Current in Recent 50 Years of Breeding Rice in China. Chinese Science Bulletin, 51, 693-699. (in Chinese) 
http://dx.doi.org/10.1007/s11434-006-0681-8

[6] Wei, X., Yuan, X., Yu, H., Wang, Y., Xu, Q. and Tang, S. (2009) Temporal Changes in SSR Allelic Diversity of Major Rice Cultivars in China. Journal of Genetics and Genomics, 36, 363-370. http://dx.doi.org/10.1016/S1673-8527(08)60125-3

[7] Moon, H.S., Nicholson, J.S., Heineman, A., Lion, K., Hoeven, R.V., Hayes, A.J. and Lewis, R.S. (2009) Changes in Genetic Diversity of US Flue-Cured Tabacco Germplasm over Seven Decades of Cultivar Development. Crop Science, 49, 498-508. http://dx.doi.org/10.2135/cropsci2008.05.0253

[8] Fu, Y.B. and Somers, D.J. (2009) Genome-Wide Reduction of Genetic Diversity in Wheat Breeding. Crop Science, 49, 161-168. http://dx.doi.org/10.2135/cropsci2008.03.0125

[9] Tu, M., Lu, B., Zhu, Y.Y. and Wang, Y. (2007) Abundant Within-Varietal Genetic Diversity in Rice Germplasm from Yunnan Province of China Revealed by SSR Fingerprints. Biochemical Genetics, 45, 789-801. http://dx.doi.org/10.1007/s10528-007-9118-6

[10] Pringle, J.S. (1975) The Concept of Cultivar. Journal of Arboriculture, 2, 30-34.

[11] Trehane, P. (1995) International Code of Nomenclature for Cultivated Plants (ICNCP or Cultivated Plant Code): Adopted by the International Commission for Cultivated Plants. Quarterjack Pub, Wimborne, 1-10.

[12] International Rice Research Institute (IRRI) (1967) Annual Report for 1966. International Rice Research Institute, Manila, 59-82.

[13] Guangdong Academy of Agricultural Sciences (1966) The Result of Semi-Dwarf Cultivar Breeding in Rice of Guangdong Province. Acta Agronomica Sinica, 5, 33-40. (in Chinese)

[14] Zou, J.S. and Lu, C.G. (2005) Practice and Thinking on Rice Breeding for High Yield. Acta Agronomica Sinica, 31, 254-258.

[15] Yuan, L.P. (1966) The Sterile Line of Rice. Chinese Science Bulletin, Issue 6, 185-188. (in Chinese)

[16] Borlaug, N.E. (1983) Contributions of Conventional Breeding to Food Production. Science, 219, 689-693. http://dx.doi.org/10.1126/science.219.4585.689

[17] National Rsearch Council (1978) Conservation of Germplasm Resources: An Imperative. National Academy of Sciences Press, Washington DC.

[18] Editing Commission for Agricultural Almanac of China (2006) Agricultural Statistical Almanac of China. China Agricultural Press, Beijing, 376-378. (in Chinese)

[19] Toenniessen, G., Adesina, A. and DeVries, J. (2008) Building an Alliance for a Green Revolution in Africa. Annals of the New York Academy of Sciences, 1136, 233-242. http://dx.doi.org/10.1196/annals.1425.028

[20] Kesavan, P.C. and Swaminathan, M.S. (2008) Strategies and Models for Agricultural Sustainability in Developing Asian Countries. Philosophical Transactions of the Royal Society B, 363, 877-891. http://dx.doi.org/10.1098/rstb.2007.2189

[21] Wolfe, M.S. (1985) The Current Status and Prospects of Multiline Cultivars and Variety Mixtures for Disease Resistance. Annual Review of Phytopathology, 23, 251-273. http://dx.doi.org/10.1146/annurev.py.23.090185.001343

[22] Marshall, D.R. and Weir, B.S. (1985) Multiline Varieties and Diseases Control. Theoretical and Applied Genetics, 69, 463-474. http://dx.doi.org/10.1007/BF00251086

[23] Mundt, C.C. (2002) Use of Multiline Cultivars and Cultivars Mixture for Disease Management. Annual Review of Phytopathology, 40, 381-410. http://dx.doi.org/10.1146/annurev.phyto.40.011402.113723

[24] Zhu, Y.Y., Chen, H.R., Fan, J.H., et al. (2000) Genetic Diversity and Disease Control in Rice. Nature, 406, 718-722. http://dx.doi.org/10.1038/35021046

[25] Ghaouti, L. and Link, W. (2009) Local vs. Formal Breeding and Inbred Lined vs. Synthetic Cultivar for Organic Farming: Case of Vicia faba L. Filed Crops Research, 110, 167-172. http://dx.doi.org/10.1016/j.fcr.2008.07.013

[26] McDonald, B.A. and Linde, C. (2002) The Population Genetics of Plant Pathogens and Breeding Strategies for Durable Resistance. Euphytica, 124, 163-180. http://dx.doi.org/10.1023/A:1015678432355

[27] Li, X. (2005) A Method for the Formation of Colony Varieties of Multi-Genotype Varieties and Production of Their Seeds. Australian Patent No. 2005333888.

[28] Li, X. (2013) The Method of Formation of F1-Colony and Seed Produce in Crops. China Patent No. 200910038179.9.

[29] International Rice Genome Sequencing Project (IRSP) (2005) The Map-Based Sequence of the Rice Genome. Nature, 1436, 793-800.

[30] Jenkins, M.T., Robert, A.L. and Findley, W.R. (1954) Recurrent Selection as a Method for Concentrating Genes for Resistance to Helminthosporium Turcicum Leaf Blight in Corn. Agronomy Journal, 46, 89-94. http://dx.doi.org/10.2134/agronj1954.00021962004600020010x 
[31] Avey, D.P., Ohm, H.W., Patterson, F.L. and Nyquist, W.E. (1982) Three Cycles of Simple Recurrent Selection for Early Heading in Winter Wheat. Crop Science, 22, 908-912. http://dx.doi.org/10.2135/cropsci1982.0011183X002200050002x

[32] Lammerts, V.B.E. (2002) Organic Plant Breeding and Propagation: Concepts and Strategies. Ph.D. Thesis, Wageningen University, Wageningen.

[33] Mao, J., He, M. and He, Z. (1991) The Effect of Mix-Cultivated Rice Varieties for Resistant of Major Diseases. Acta Phytopothologica Sinica, 121, 155-160.

[34] Li, X. (2012) Method for Preventing Mutation of Pathogens Exposed to Transgenic Plants. US Patent No. 8101822.

[35] Li, X. (2011) A Method for Constitution and Production of Multi-Genotype Colony Varieties in Crop Plants. Eurasian Patent No. 015824.

[36] Li, X., Liu, Z., Lu, D., Liu Y., Mao, X., Li, Z. and Li, H. (2013) Development and Evaluation of Multi-Genotype Varieties of Rice Derived from MAGIC Lines. Euphytica, 192, 77-86.

[37] Li, Z., Ye, G., Yang, M., Liu, Z., Lu, D., Mao, X., Wu, Q. and Li, X. (2014) Genetic Characterization of a Multiparent Recombinant Inbred Line Rice Population. Research on Crops, 15, 28-37.

[38] Tang, Z., Li, X., Zhuang, G., Jing, X. and Lu, D. (2007) Searching for the Corelative Factors of Photo-Sensitiveness and Temperature Sensibility in Rice. Guangdong Agricultural Sciences, 4, 7-10.

[39] Tang, Z., Jin, X., Li, X., Liu, Y., Liu, Z., Lu, D., Mao, X., et al. (2010) Preliminary Analysis on Rice Blast Disease and Genetic Diversity of Its Pathogen in Multi-Genotype and Mono-Genotype Varieties. Acta Agronomica Sinica, 36, 1791-1795.

[40] Revilla-Molina, L.M., Bastiaans, L. and Keulen, H.V. (2009) Does Resource Complementarity or Prevention of Lodging Contribute to the Increased Productivity of Rice Varietal Mixture in Yunnan China? Field Crops Research, 111, 303-307. http://dx.doi.org/10.1016/j.fcr.2009.01.003

[41] Li, X.F. (2012) Multi-Genotype Variety Breeding in Crop Plants and Strategy of Seed Production. Chapter 1, Science Publisher, Beijing, 1-36. 